\title{
ESTUDIO Y RESTAURACIÓN DEL SABLE EN ACERO DE DAMASCO DE MEHEMET ALÍ
}

\author{
POR \\ A. Moyano, F. Ferro, G. GonZÁlez, R. CAlabrés, D. Arias, \\ J. M. JiMÉNEZ, J. A. MARTÍNEZ y A. J. CRIADO
}

\section{RESUMEN - ABSTRACT}

El presente artículo trata sobre el estudio y restauración del sable perteneciente a Mehemet Alí. Este trabajo se ha realizado bajo dos enfoques diferentes: científico e histórico. El primero, en donde se han desvelado los secretos internos de este maravilloso y genuino acero de Damasco, tan admirado por el poder de sus espadas como por la belleza de las aguas y damasquinados presentes en las mismas. Para ello nos hemos ayudado de técnicas como la Microscopía Óptica, Microscopía Electrónica de Barrido (MEB), ICP Masas y Ultrasonidos. Bajo el segundo enfoque, se ha realizado un seguimiento histórico de Mehemet Alí, y su contribución al Egipto de los siglos XVIII y XIX.

The present manuscript is about study and restoration of a sabre, which belonged to Mehemet Ali. The work has been adopted a scientific and a historical approach. Scientific one has revealed the secrets of Damascus steel, so admired by the power of their swords as well as by the beauty of their beautiful markings, and damascene works. Techniques such as Optical Microscopy, Scanning Electron Microscopy (SEM), ICP Mass and Ultrasonic have been used in order to achieve this scientific research. Historical approach has carried out a work about the contribution of Mehemet Ali, especially to Egypt in the 18th and 19th centuries.

\section{PALABRAS CLAVE - KEY WORDS}

Acero de Damasco. Alfanje. Shamshir. Assad Allâh Isfahânî. Mehemet Alí. Egipto.

Damascus Steel, Cutlass, Shamshir, Assad Allâh Isfahânî. Mehemet Alí, Egypt.

\section{INTRODUCCIÓN}

En la Colección de armamento musulmán conservada en el Museo Nacional del Ejército se encuentra un alfanje, que por sus características llamó la atención del Prof. Dr. Antonio José Criado Portal. Se solicitó el correspondiente permiso para estudiar y restaurar el arma, y el estudio que aquí presentamos, es el resultado de dicha investigación.

Nuestro punto de partida fue la somera información recogida en una ficha documental del Museo, que transcribimos a continuación:

\section{Reseña del Museo del Ejército}

\author{
PLANTA: Infantería \\ SALA:Árabe \\ $N^{\circ}$ DEL CATÁlOGO 24.912, Tomo I, Página 246 (Antiguo: $N^{\circ}$ 1921, Tomo IV, Página 515). \\ VITRINA 2
}




\section{HISTORIA:}

«Que perteneció a Mehemet Alí, Bajá de Egipto. Tiene la empuñadura de asta de rinoceronte, hoja damasquinada, fabricada en el año 870 de la Hégira (1465 d.C.) y vaina de terciopelo verde con contera, boquilla y abrazadera de hierro grabado y dorado. Fue regalado por su dueño al Cónsul español en Alejandría, D. Antonio Estéfani, y por éste al Capitán de Artillería D. Joaquín Bouligni quien la cedió al Museo en 1848».

El equipo de científicos e historiadores dirigidos por el Dr. Antonio José Criado Portal, organizó su trabajo en dos áreas de estudio complementarias. La primera consistió en la búsqueda e interpretación de fuentes y otros datos que permitieran conocer el marco histórico que rodeó al alfanje. La segunda, en el análisis químico y restauración del arma. Ambas han permitido la puesta en valor, dentro del propio Museo del Ejército, de un objeto cuya importancia se desconocía.

Ahora, con este artículo, ponemos a disposición de la Comunidad Científica una información y algunas propuestas, que ojalá aporten datos de interés para sucesivos estudios.

\section{DESCRIPCIÓN, ANÁLISIS QUÍMICOS EFECTUADOS Y RESTAURACIÓN DEL SABLE DE MEHE-} MET ALÍ

El Shamshir objeto de nuestro estudio es un arma de hoja damasquinada, con empuñadura de asta de rinoceronte curvada hacia abajo (Fig. 1). Esta forma de empuñadura, que los árabes usan ya en los siglos VIII-IX, aparece en Persia más tarde. Las primeras imágenes que conocemos de armas de estas características en Persia, son de monedas de 1184-1201 d.C. (Stocklein 1938:2571). Este sable tiene una longitud de $933 \mathrm{~mm}$ y un grosor y un ancho, tomadas en su parte central de 5,95 y $31,4 \mathrm{~mm}$ respectivamente.

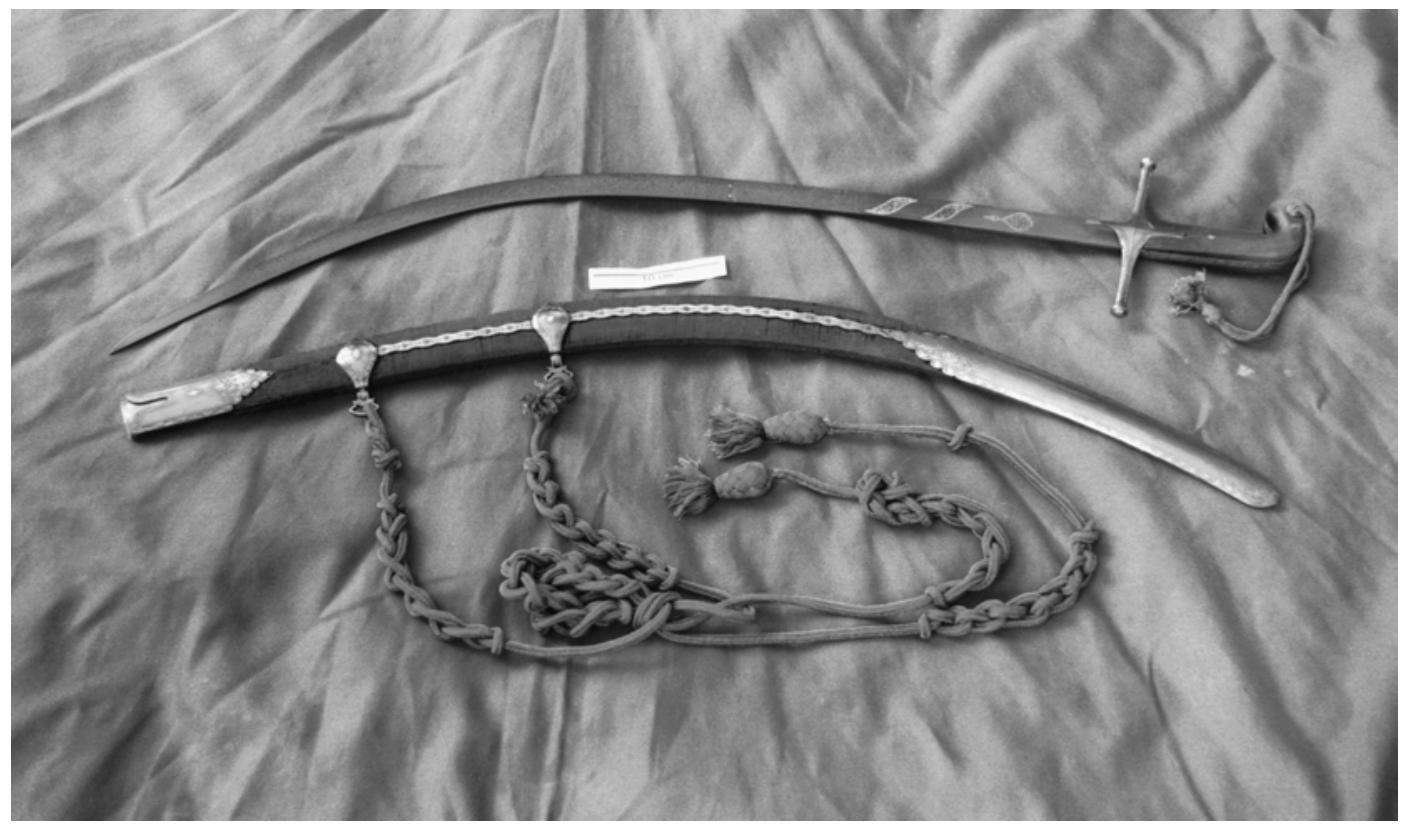

Fig. 1. Alfanje de Mehemet Alí. Museo del Ejército, Madrid. 
La cruceta está dividida en cuatro cuadrantes con proyecciones laterales (Fig. 2). La hoja, está protegida por una vaina de terciopelo verde con contera, boquilla y abrazadera de hierro grabado y dorado.

Con el fin de desvelar la estructura y composición química de la hoja, se sometió a la misma a los siguientes y pormenorizados análisis químicos, metalográficos y ensayos no destructivos:

- Ablación por Láser

- Espectrometría de Masas con fuente de Plasma de Acoplamiento Inductivo (ICP).

- Microscopía Óptica y Electrónica de Barrido

- Ultrasonidos

- Dureza Superficial

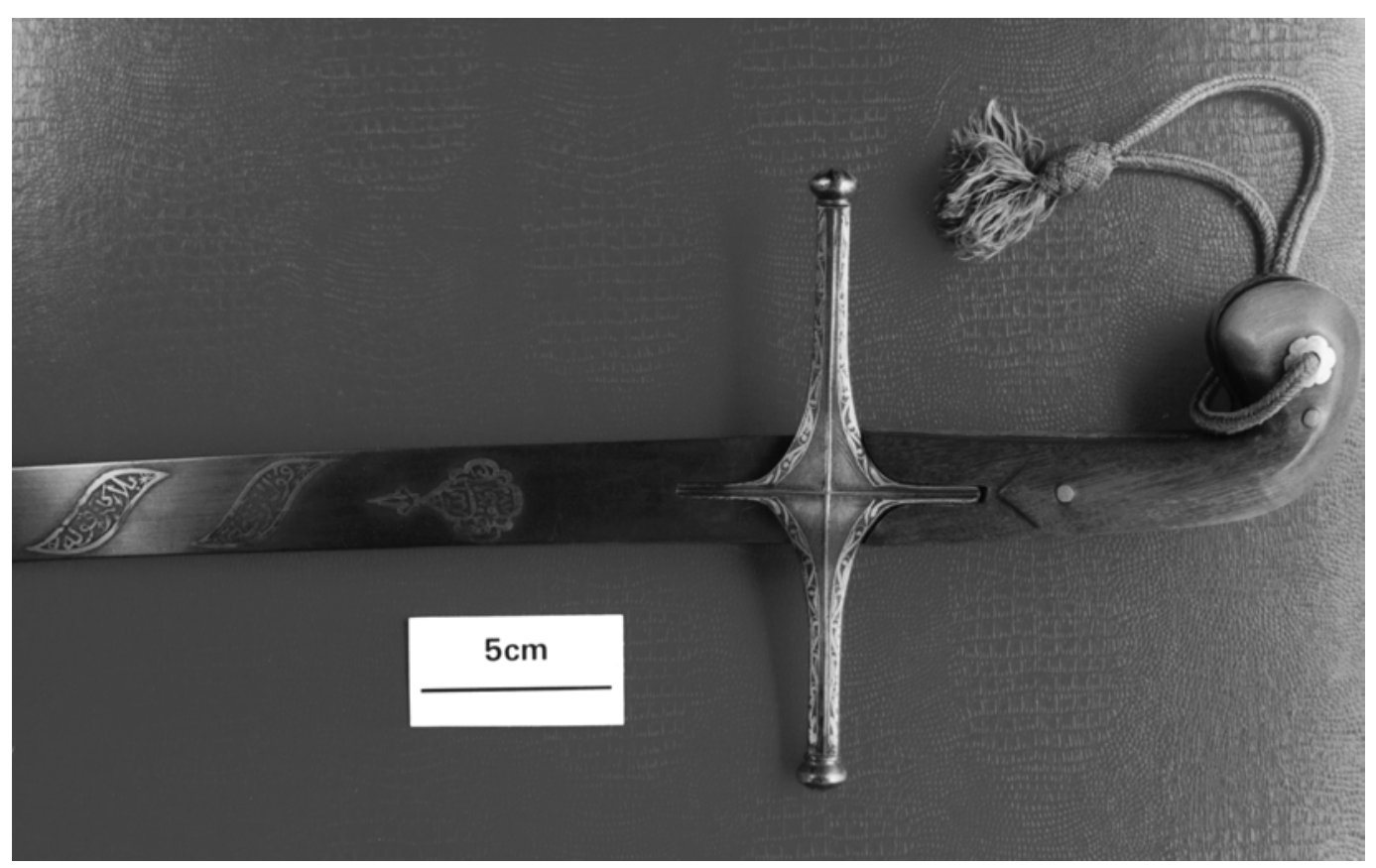

Fig. 2. Detalle de la empuñadura del alfanje, mostrando en primer término la cruceta.

Un genuino Acero de Damasco es un acero con un contenido en carbono entre un 1,4 y un $2,1 \%$ en masa, el cual, dependiendo del tipo de tratamiento térmico final y posterior ataque químico, presenta las características vetas sinuosas, formadas por carburos de hierro (Fig. 3). Se fabricaba en una fundición única y en las distintas etapas de procesado se sacaba el carbono en forma de carburo de hierro mediante segregación discontinua, siendo el resultado de un proceso repetitivo y complejo de calentamientos y forja en caliente.

De los análisis químicos y ensayos metalográficos realizados se deduce que el acero de la hoja del sable de Mehemet Alí posee una microestructura que se ajusta al legítimo Acero de Damasco, presentando las vetas sinuosas de carburos, características de este tipo de acero (Fig. 4). Su composición en carbono de $1,65 \%$ en peso y los bajos límites de las impurezas demuestran una ajustada fabricación del acero. La forja y el temple cumplen los requisitos transmitidos por la tradición y la alquimia. 

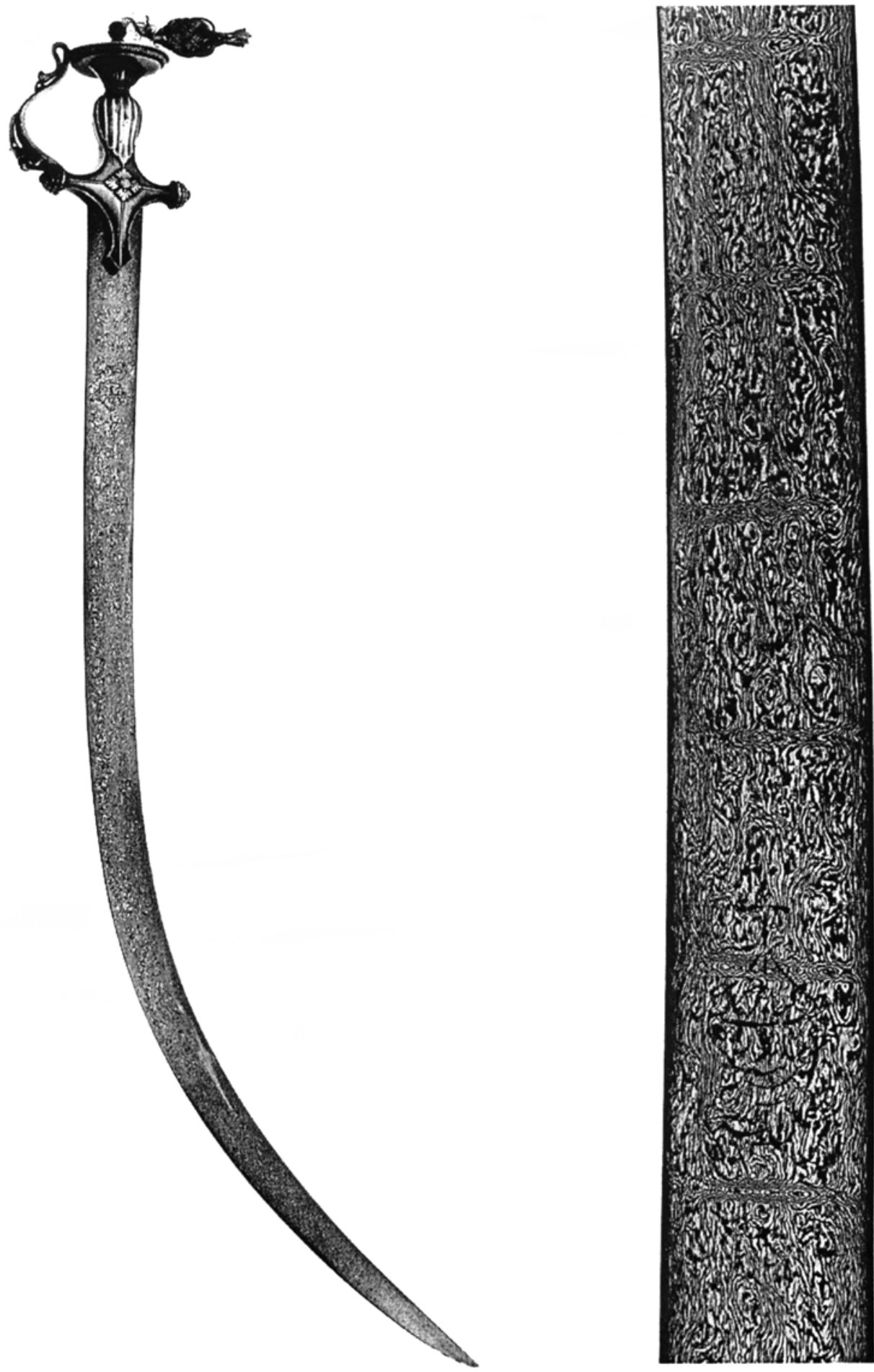

Fig. 3. Fotografía de un bello ejemplar de Shamshir persa, obra del maestro herrero Assad Allâh al- Isfahânî, donde se pueden observar las famosas «Escaleras de Mahoma». 


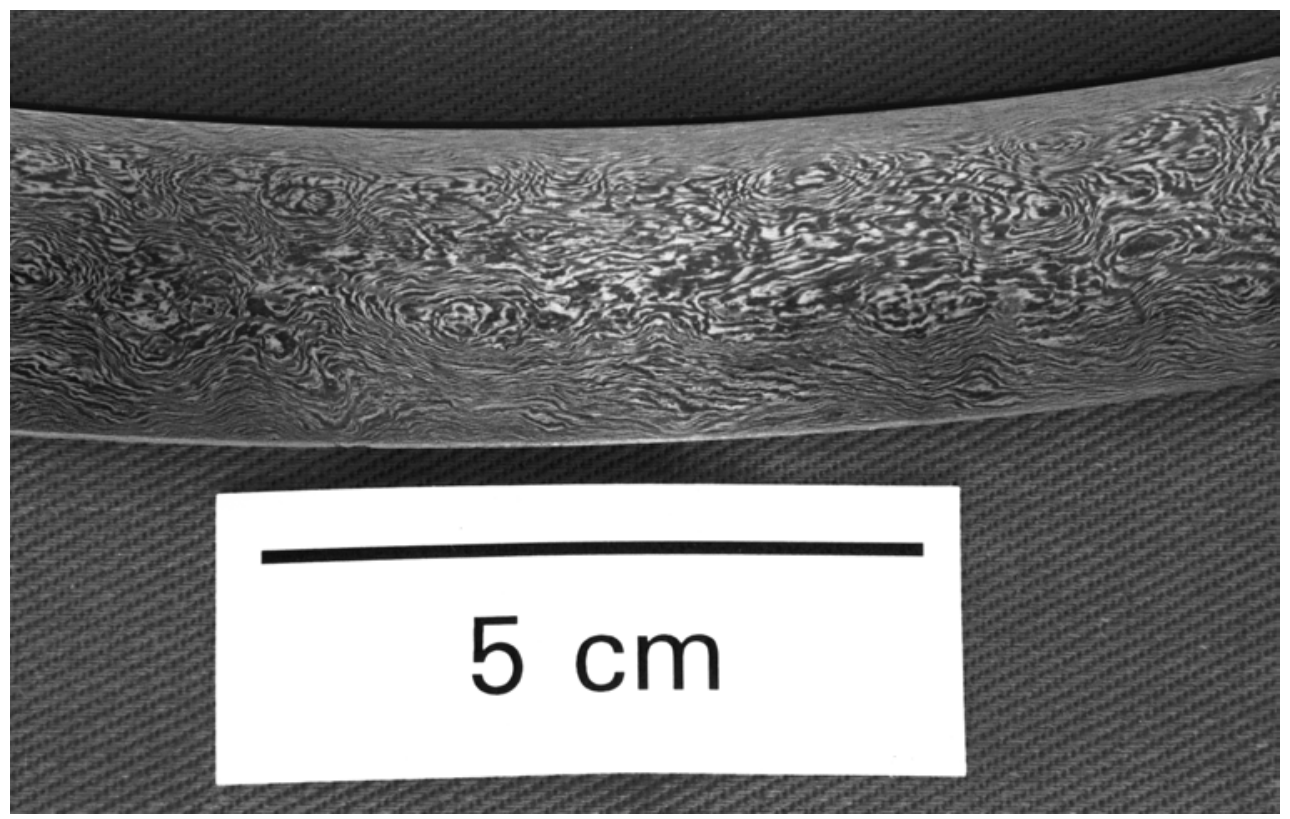

Fig. 4. Detalle de las vetas sinuosas de carburos en la parte central de la hoja del sable.

La Microscopía Electrónica de Barrido ha permitido comprobar que la hoja fue forjada cuidadosamente a temperaturas que oscilaron entre el rojo sangre y el rojo cereza (650$750^{\circ} \mathrm{C}$ ). El proceso de forja a temperaturas bajas, provoca una esferoidización interna de la cementita, tanto proeutectoide como de la eutectoide (Figs. 5 y 6). Desbastada a la piedra y pulida, la hoja de acero fue damasquinada en oro (Fig. 7) con leyendas cerámicas y la fecha de ejecución, además de la firma o marca del fabricante. Finalmente fue atacada con un oxidante enérgico en medio ácido, como el sulfato férrico (tierra de Damasco) con ácido de manzana (málico) o cítrico.

La técnica de fabricación del acero de Damasco es sólo un recuerdo a comienzos del siglo XIX, como comprueba el viajero Domingo Badía (Alí Vey) durante su visita a Siria (Badía,1996: 642) entre los años 1806 y 1807:

«También los armeros forman un ramo considerable de la industria del país, aunque no existe ya la célebre manufactura de los sables damasquinos. El temple de los que al presente se fabrican no es superior al de los demás sables de Turquía (...). Los sables de la antigua fábrica pasan de mano en mano y se miran como cosa preciosa; por consiguiente el precio es exorbitante, y depende enteramente del capricho. Después de estos sables antiguos, los más estimados son los de la fábrica de Khorassan en Persia»

La conservación anterior al estudio ha sido del todo incorrecta, presentando deterioros notables en la hoja acerada y damasquinados en oro en general, debido fundamentalmente a la utilización de productos abrasivos y a no haber previsto la corrosión propia de ambientes húmedos y agresivos.

Para su restauración (Figs. 8 y 9), se trató de llevar la superficie de la hoja acerada a su estado original, mediante desbaste con papel abrasivo con una granulometría que iba desde el 400 al 1200 , realizando un posterior pulido con alúmina $\alpha(0,3 \mu \mathrm{m})$ y alúmina $\gamma(0,05$ $\mu \mathrm{m})$, ambas en suspensión acuosa.

Para el resto de elementos metálicos del sable y vaina, todos en acero suave con damasquinados en oro, se utilizó para su limpieza una antigua fórmula alquímica a base de zumo de 


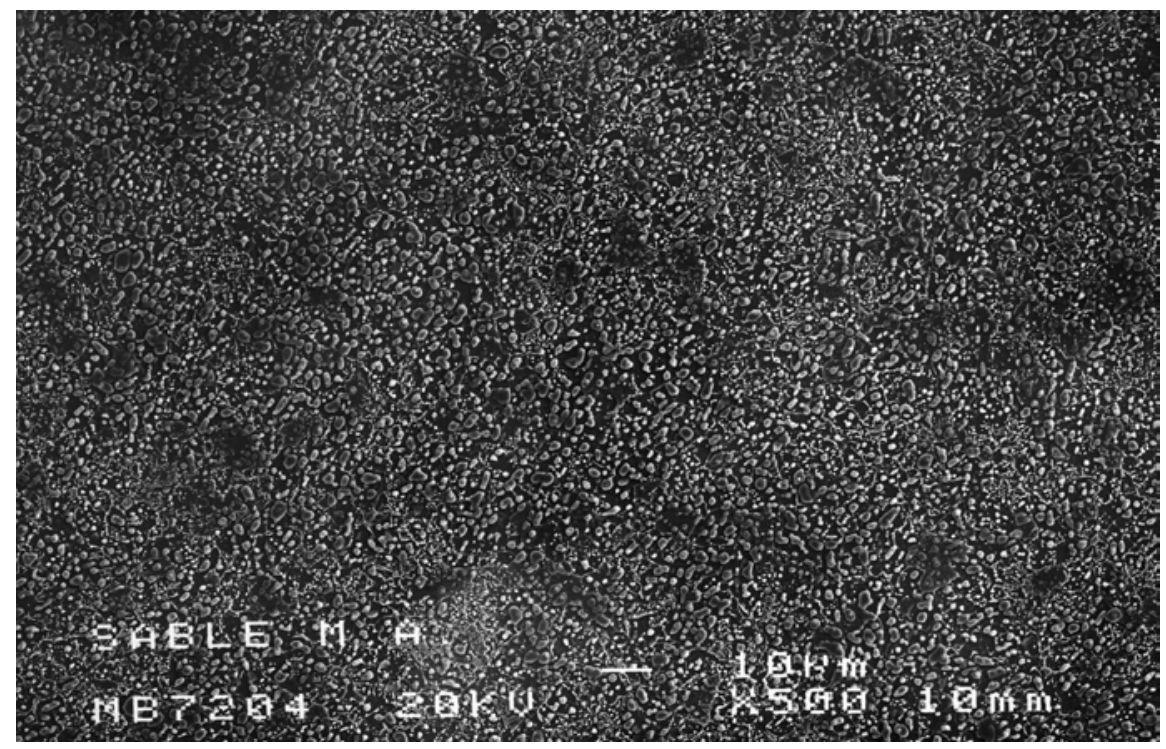

Fig. 5. Micrografía en la que se muestra la estructura interna del acero de Damasco del alfanje de Mehemet Alí..

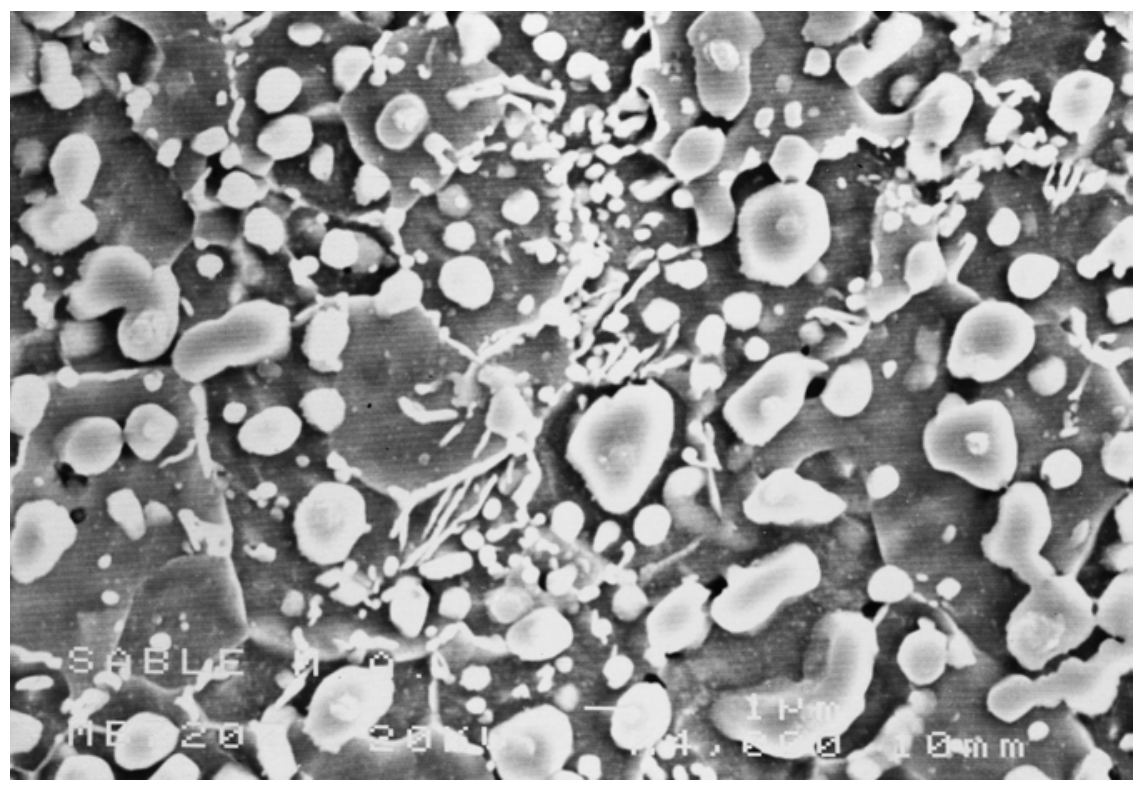

Fig. 6. Detalle de la figura anterior, en donde se observan los carburos de hierro casi totalmente esferoidizados, debido a los diferentes tratamientos termomecánicos llevados a cabo en la hoja.

de manzana ácida, cera de carnauba y jabón a base de aguas carbonatadas de lixiviación de cenizas de madera. Esta receta de sustancias naturales, nada agresivas, eliminó el óxido sin deterioro del acero base, dejando una pátina de cera protectora después de su lavado en agua y posterior secado. 


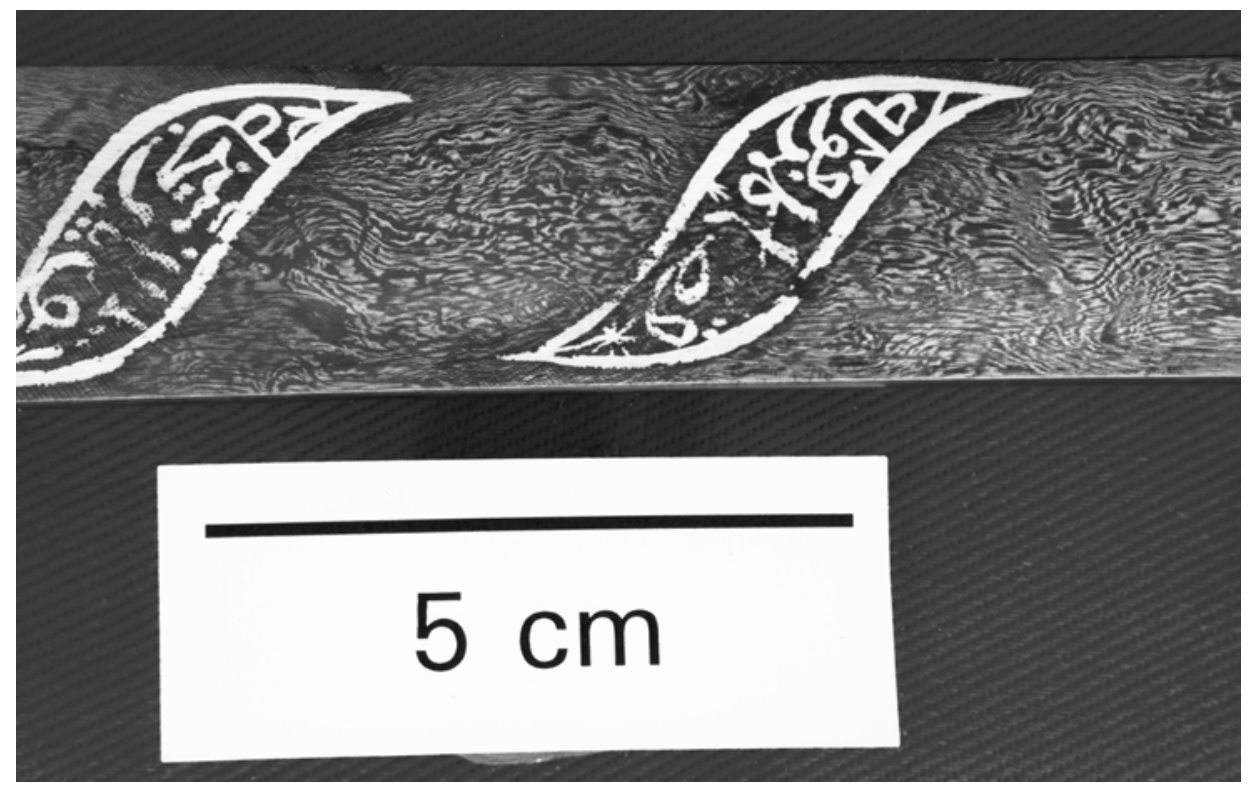

Fig. 7. Detalle de los damasquinados en oro después del proceso de restauración.
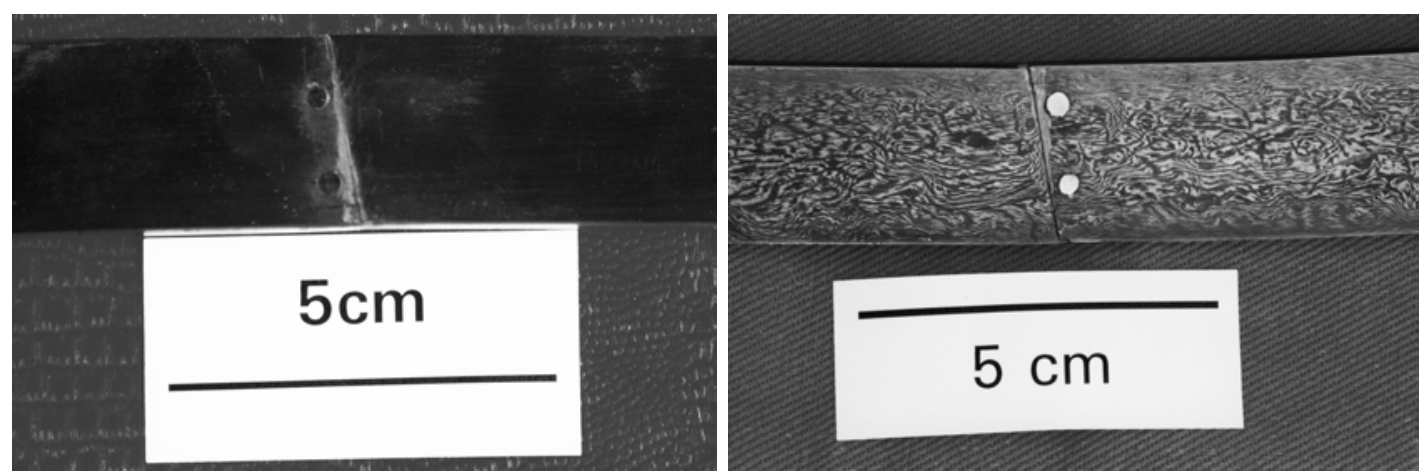

Fig. 8. Detalle de la zona central, antes y después del proceso de restauración, en la cual se puede observar la presencia de dos remaches producto de la rotura de la hoja.
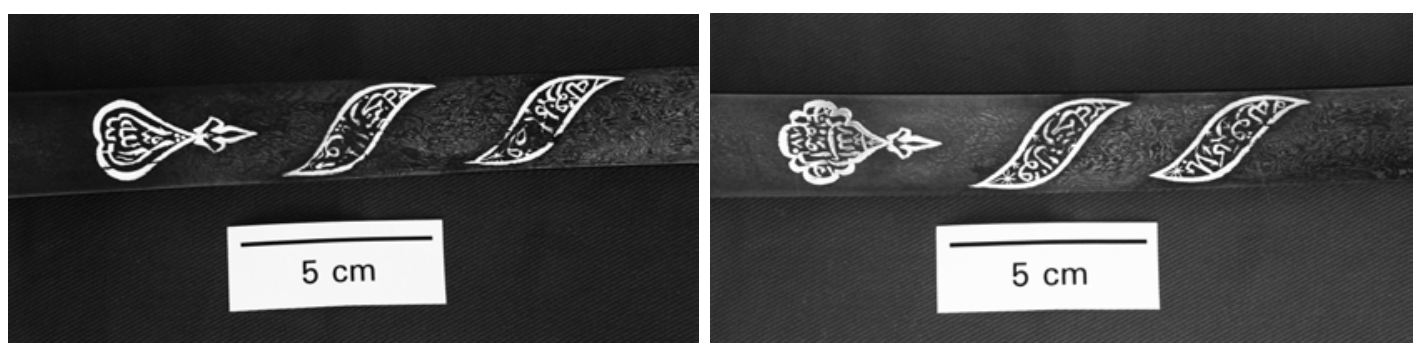

Fig. 9. Detalle de los damasquinados en oro en los dos lados de la hoja una vez restaurados 
La hoja acerada, después de limpia y examinada, se atacó con Nital al 4\% (ácido nítrico concentrado al $4 \%$ en disolución alcohólica), reactivo semejante al legendario ataque con tierra de Damasco (Sulfato Férrico en disolución acuosa acidificada con ácido cítrico) o a otro, igualmente antiguo, a base de arsénico y zumo de toronja. La ventaja del Nital es su limpieza y control de futuras agresiones al acero por residuos depositados difícilmente eliminables, inherentes a los otros reactivos de ataque.

El ataque químico, desigual según el diferente tratamiento térmico de las diversas partes de la hoja acerada, puso de manifiesto la bellísima estructura de vetas serpenteantes debido a las fibras de carburo de hierro. Para que la belleza del ataque se conserve sin que la oxidación pueda deteriorarlo, se recubrió con laca zapón. Esta laca nitrocelulósica en acetona, con varios siglos de antigüedad en su uso, aporta una buena protección contra cualquier agente atmosférico y puede eliminarse con un paño impregnado en acetona, alcohol o tricloroetileno.

\section{LA INSCRIPCIÓN DEL SABLE. PECULIARIDADES DE SU FABRICACIÓN Y ORIGEN}

En ambas caras de la hoja aparecen damasquinadas en oro leyendas cerámicas cuya transcripción y traducción es la siguiente:

1. Cara «a», orla superior

«Es incuestionable Su dicho (Su palabra)»

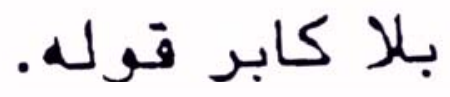

2. Cara «a», orla intermedia

«El dicho es Su tiempo»

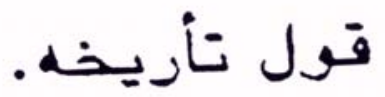

3. Cara «a», orla inferior

«Fabricada por Assad Allâh Isfahânî

870 H. $(1465 / 1466$ d.C. $) \gg$

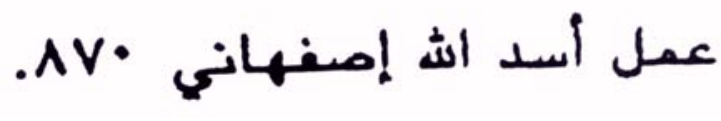

4. Cara «b», orla superior

«Es incuestionable Su dicho»

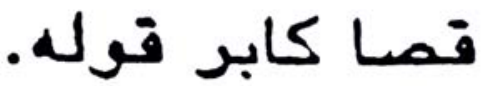

5. Cara «b», orla intermedia

«Su tiempo es real»

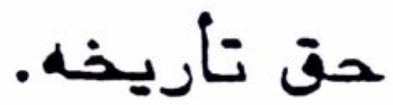

6. Cara «b», orla inferior

«Si Dios quiere»

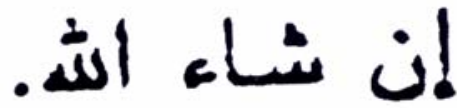

Por lo tanto, y según la inscripción del arma, esta es obra de Assad Allâh Isfahânî, una firma que está contenida en cientos de espadas persas. Este armero, del que Mayer (1962:26) dice que es « (...) by general consent of Easternand Western opinion, the finest of all Persian swordsmiths», plantea enseguida una dificultad al intentar adscribirle a una época concreta.

La tradición ha querido encuadrar cronológicamente a este personaje dentro del período de Shâh Abbâs I de Persia, quien gobernó entre 1587 y 1629, y perteneció a la dinastía de los safawíes.

A nuestros días ha llegado una anécdota (Lambton, 1954:25), según la cual el Sultán Otomano presentó a Shâh 'Abbâs I un yelmo, y ofreció una suma de dinero a quien pudiera partirlo en dos con una espada. Assad Allâh de Isfahân, ciudad convertida por el Shâh en la 
capital del reino, fabricó una espada con la que partió el yelmo. Como recompensa, Shâh Abbâs I eximió del pago de impuestos a todos los fabricantes de espadas, exención que se mantuvo hasta la época de Kadjar.

No habría ningún problema en dar por buena la noticia, a pesar de la vaguedad con que presenta a nuestro fabricante de armas, de no ser porque conocemos armas firmadas por Assad Allâh en un período que abarca casi cuatro siglos. Mayer (1962:27) señaló en su momento que el arma más antigua conocida de este maestro armero estaba fechada en $811 \mathrm{H}$ (comienzos del siglo XV de la era cristiana), y la más reciente en 1808 d.C. El mismo alfanje que estudiamos aquí está fechado en $870 \mathrm{H}$.

Podría pensarse razonablemente que las armas firmadas por Assad AIIâh con posterioridad a la primera mitad del siglo XVII — fecha en la que ya no viviría el maestro armero que trabajó para Shâh 'Abbâs I- o bien son falsificaciones o bien para entonces la firma Assad Allâh Isfahânî no correspondía a ningún personaje histórico, sino que equivaldría a una marca de taller armero. Pero, ¿qué hacer con respecto a las espadas fechadas con anterioridad?

Nuestra opinión es que, de haber existido un fabricante de espadas — un shamshirsazcon dicho nombre, y no hay por qué dudar de ello en principio, tendría que haber vivido como muy tarde a comienzos del siglo IX de la Hégira y habría creado un estilo propio en la elaboración de armas blancas y fundado consecuentemente una escuela, que perviviría hasta finales del siglo XIX.

En la época de Shâh 'Abbas I, hubo un tal Assad Allâh que ocupó el cargo de sadr, palabra que en árabe significa pecho, pero que en la Persia safávida era el nombre con que se designaba un cargo similar al de Primer Ministro. Este Assad Allâh no tenía nada que ver con el nombre que aparece en el alfanje, pues además de ser un hombre de Estado - y no un maestro herrero- no era de Isfahân.

El Assad Allâh que vivió bajo el reinado de Shâh 'Abbâs I podría ser un descendiente suyo y/o el titular de ese Taller.

En base a estos principios, el alfanje de Mehemet Alí sería una de las más antiguas creaciones del artista Assad Allâh Isfahânî, pues está datado en el año 870H (1465-1466 d.C.). Si tenemos en consideración el catálogo de espadas de este fabricante elaborado por Mayer (1962:27-29), el arma que estamos tratando es la segunda más antigua de cuantas poseen algún tipo de datación. Mayer incluye en su listado, en el que no aparece la pieza de Mehmet Alí que nos ocupa, 15 armas con la firma de Assad Allâh y la fecha de fabricación.

\section{PARALELISMO HALLADO CON OTRAS ARMAS}

En su aspecto externo, el arma que estudiamos presenta similitudes significativas con una espada del Museo de Arte Islámico de El Cairo, en lo referente a la forma de la hoja, la cruceta y la empuñadura. Ambas tienen la hoja de forma curva. Ambas crucetas, muy parecidas a simple vista, están divididas en cuatro cuadrantes con proyecciones laterales, si bien difieren en la terminación -formas ovoides en el caso de la espada de El Cairo- . Las empuñaduras, de formas iguales, están realizadas en asta. En el caso del alfanje de Mehemet Alí, la perfección de la ejecución en la empuñadura podría sugerir una fabricación de tipo industrial. De ser así, cabría la posibilidad de que la empuñadura antigua, fabricada a la vez que el resto del arma, hubiera sido sustituida posteriormente imitando la forma anterior. La presencia en el centro de su extremo redondeado de una roseta dorada, decoración típica otomana, podría afianzar esta hipótesis.

La espada de El Cairo está catalogada como «de arte mameluco» (Esin, 1981: 114-115), y fue fabricada hacia el año 1501 d.C., unos 35 años después que la del Museo del Ejército. Perteneció al sultán mameluco Tumambay I. 
En las ilustraciones realizadas por el equipo de científicos que acompaña a Napoleón Bonaparte en la expedición a Egipto, bajo los epígrafes «Costumes et portraits» y «Vases, meubles et instruments» (VV.AA., 1994:728 y 742. Ilustraciones 6-7) aparecen como «Armas Mamelucas» varios sables que presentan un notable parecido con el alfanje que estudiamos. Especialmente digno de resaltar es el objeto $\mathrm{n}^{\circ} 6$ que aparece bajo el segundo epígrafe de los citados (Fig. 10). El arma está en su vaina, y las analogías con la espada del Museo del Ejército en cuanto a ésta última, así como la cruceta y la empuñadura son evidentes.

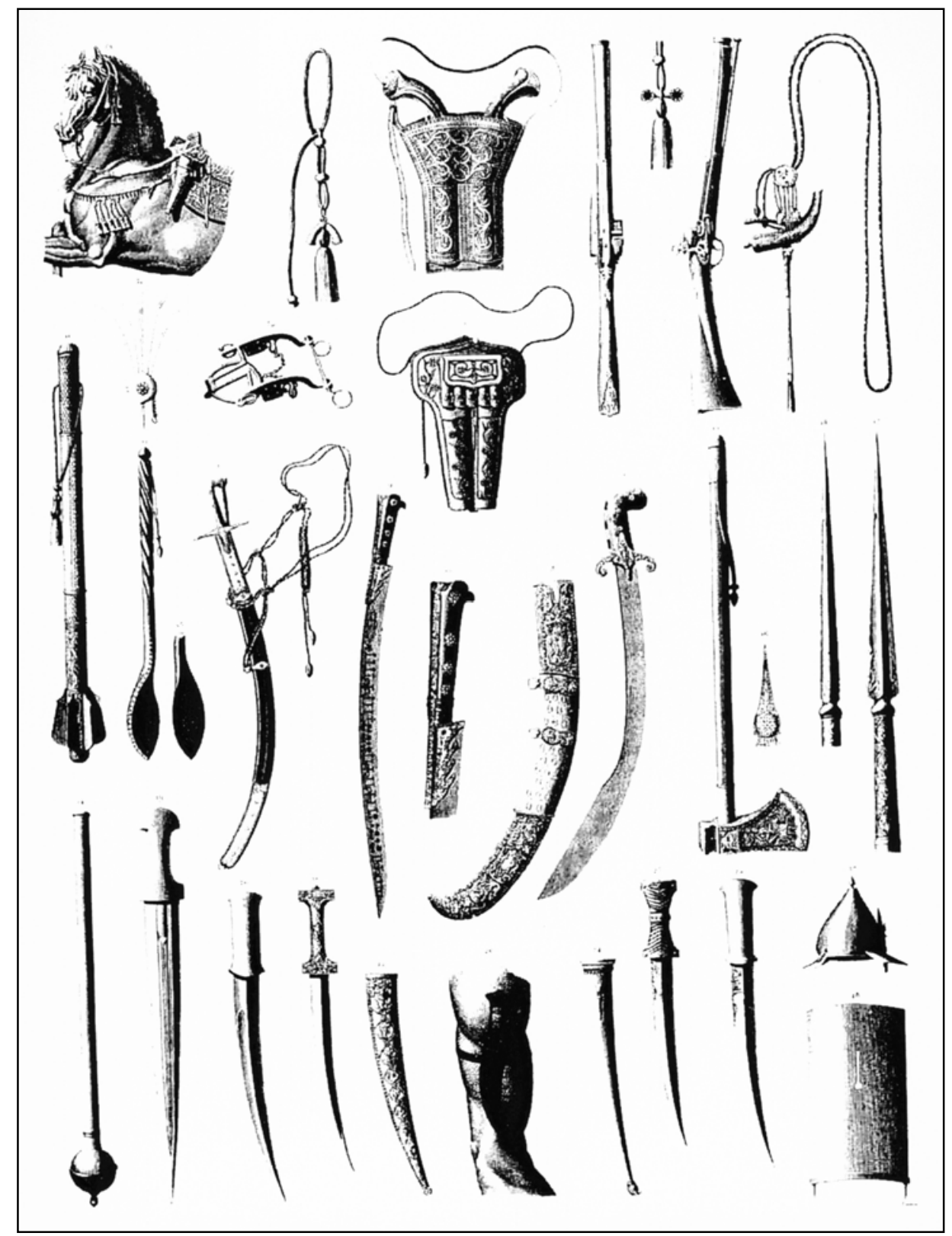

Fig. 10. Apuntes de armas mamelucas realizadas por el equipo de científicos que acompañaron a Napoleón. 
La vaina que protege el alfanje de Mehemet Alí tiene los anillos en forma de escudo en un lado de la funda (Fig. 1) .Esta peculiaridad apunta, como indica Stocklein (1938:2572) otra analogía con las armas mamelucas, que también presentan ese tipo de anillos.

\section{HISTORIA RECIENTE DEL SABLE: MEHEMET ALÍ, PADRE DEL EGIPTO MODERNO}

Tal como consta en el Archivo del Museo del Ejército, el sable objeto de esta investigación perteneció a Mehemet Alí, militar y hombre de Estado a quien se considera el iniciador de la modernización de Egipto, merced a la política innovadora que llevó a cabo, especialmente en el ámbito económico (Fig. 11).

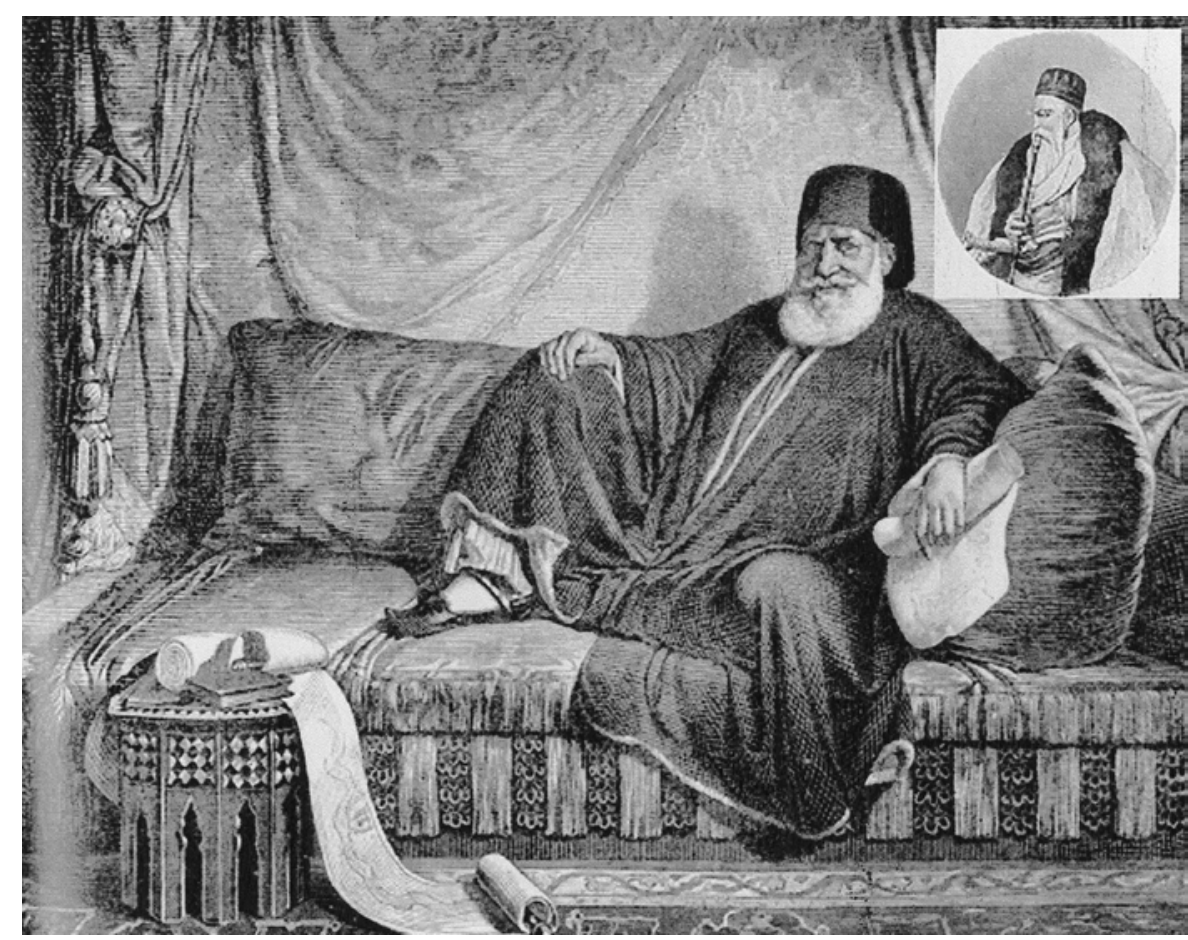

Fig. 11. Grabado de la época en el que se muestra al Sultán egipcio Mehemet Alí, último propietario musulmán del alfanje y que ha dado nombre a la pieza.

\subsection{Mehemet Alí en su contexto histórico y político}

Mehemet Alí nació en Cavalla, ciudad de Grecia situada cerca de Macedonia, frente a la isla de Tasos, en 1769, aunque su familia era de origen albanés. Murió en la ciudad egipcia de Alejandría en 1849. Su presencia en Egipto está relacionada con el envío, por parte del Imperio Otomano y en los últimos años del siglo XVIII, de un cuerpo de ejército albanés a este país, para luchar contra Napoleón. Grecia y Albania formaron parte del Imperio Otomano desde comienzos del siglo XV: ello explica que Mehemet Alí, griego de origen albanés, 
pase a Egipto al mando de tropas otomanas. Era, en realidad, un converso, figura no muy frecuente en la época.

Egipto formaba parte del Imperio Otomano desde 1517, año en que se convirtió en provincia imperial tras la derrota de los mamelucos, llevada a cabo por el sultán Selim. A partir de entonces, la provincia fue gobernada por un Bajá - elegido anualmente- que se encargaba de la recaudación de impuestos y del reclutamiento de contingentes militares, así como de su envío a Constantinopla. La política turca respecto a Egipto provocó la decadencia de su economía, en especial por la disminución notable del comercio de especias, una de las principales fuentes de riqueza egipcia.

Por lo tanto, el país al que llega Mehemet Alí hacia 1799 era codiciado por Francia y Rusia, y vigilado por los británicos. En 1775, Inglaterra había conseguido la apertura del Mar Rojo para sus actividades comerciales, y más tarde la concesión de hacer escala en territorio egipcio para dirigirse hacia la India. Precisamente este hecho fue la excusa utilizada por Napoleón para la campaña de Egipto.

Tras la retirada del ejército francés, Mehemet Alí tomó la ciudadela de El Cairo en el año 1803, al mando de tropas turcas. Esta victoria le permitió hacerse con el poder, y fue reconocido Bajá por el Sultán. En 1806, y con motivo de una audiencia concedida por Mehemet Alí, el viajero Alí Bey (Badía,1996: 387-388) tiene ocasión de relatar una descripción física del virrey. También nos deja una interesante visión de la dependencia aparente, en esta primera fase de su gobierno, que mantiene respecto a las autoridades nombradas desde Constantinopla. Alí Bey escribe que llegó a El Cairo el lunes 10 de noviembre de 1806, por consiguiente, la visita a Mehemet Alí se realizó pocos días después:

«Devolvía las visitas a los grandes scheihs, y acompañado de Seid Omar pasé a ver al bajá Mehemet Alí, en cuyas manos puse la carta del capitán bajá. Dispensóme los mayores obsequios. Dicho príncipe, todavía joven, es de pequeña estatura y picado de viruela; es valiente, tiene los ojos vivos, y se nota en él cierto aire de desconfianza; dotado de espíritu y buen sentido carece de instrucci6n, y se halla con frecuencia embarazado; y entonces es cuando Seid Omar, que ejerce sobre él notable influencia, hace señalados servicios al pueblo y al mismo bajá»

Sin embargo, tal dependencia no impedirá a Mehmet Alí y otros bajás actuar como gobernantes autónomos, incluso en lo económico (op.cit.: 727):

«Esta indiferencia de los pueblos hacia su soberano (el gran Señor de Constantinopla) es una de las principales causas que facilitan y favorecen la rebelión de los bajaes en las provincias. Sabido es cuantos años se sostuvieron Djezzar, Paswan Oglow, Kadri Agá, etc., y vemos al presente a Mehemet Alí en Egipto, Kuchuk Alí en Siria, (. ..), los cuales, bajo un aire de dependencia de su soberano, son realmente independientes y no hacen el menor caso de los firmanes de la Puerta, cuando no conviene a sus intereses.

(...) los bajaes anteriormente nombrados apenas envían nada al tesoro público (otomano)»

El bajá, en el Imperio Otomano, estaba asistido por los beyes, o prefectos cuya designación se supervisaba desde Constantinopla. Mehemet Alí contaba con beyes mamelucos, que tenían un ejército propio y pretendían una independencia cada vez mayor respecto del Bajá. El enfrentamiento armado entre ambos no tardó en producirse, y en 1811 los beyes fueron asesinados en masa y su ejército disuelto.

En el exterior, Mehemet Alí siguió una política de expansión territorial. El mismo año de su enfrentamiento con los beyes combatió la insurrección de los wahhabies, cuyas reformas amenazaban la autoridad imperial desde el siglo XVIII, a petición de la Sublime Puerta. En árabe, Bab-I Alí: nombre de una puerta del palacio del sultán, en Estambul, cuyo nombre se aplica más tarde al gobierno del Imperio Otomano. Esta expedición le permitió extender su autoridad sobre Arabia. En 1823 se estableció en Sudán y fundó la ciudad de Jartum. 
A partir de 1831, Mehemet Alí, nombrado Virrey de Egipto desde 1804, se enfrentó al gobierno otomano primero políticamente y militarmente después, con Asia como escenario. Ibrahim Bajá, enviado a Siria por su padre, llegó a derrotar al ejército turco en 1831 y a marchar sobre Constantinopla. Siria había sido reclamada por Mehemet Alí al sultán de Constantinopla, como pago por su intervención en Grecia. Para el virrey, este país le facilitaba la protección de sus fronteras y el abastecimiento de madera para las construcciones navales. sin embargo, las potencias europeas obligaron a Mehemet Alí a firmar la Paz de Kütahya, en 1833, a cambio de la cuál se le concedió el gobierno de Siria y de Adana.

Preocupado por su política de expansión y de independencia, el gobierno otomano intentó dominarle y las hostilidades se reanudaron en 1839. Los turcos fueron vencidos en Nusaybin, y la Sublime Puerta logró salvar la situación una vez más, gracias a la intervención de las potencias europeas. Presionado por Gran Bretaña, que hizo bombardear Beirut y Acre, aquél renunció a Siria, Adana y Creta, pero, a cambio, obtuvo el gobierno hereditario de Egipto como virrey, bajo la soberanía turca, por el Tratado de Londres, firmado en 1840. Su política interior en Egipto estuvo marcada por una serie de reformas de carácter económico.

Mehemet Alí abdicó en 1848 en su hijo Ibrahim, y su dinastía Ytransformada en una Monarquía con sus últimos representantes` se perpetuó en Egipto hasta el año 1952, en que fue sustituida por una dictadura militar de signo republicano.

5.2. Mehemet Alí y los europeos: su relación con Antonio Estéfani y el Consulado de España en Alejandría.

La presencia de asesores europeos fue una constante durante el gobierno de Mehemet Alí, quien fomentó las buenas relaciones con los países europeos, en especial con Francia, a través suyo. A las propuestas de estos consejeros se deben la realización de algunas de las reformas más representativas que el Virrey acometió en Egipto. Basándose en un proyecto francés elaborado treinta años antes, Mehemet Alí posibilitó en las primeras décadas de su gobierno, la difusión entre la población egipcia de la medicina moderna y de la vacunación. Esta difusión se realizaba a través de fundaciones islámicas de carácter piadoso, cercanas por su carácter al pueblo. Es patente, así mismo, el asesoramiento en relación con las reformas que afectan a la agricultura. Mehemet Alí encargó al capitán francés Sèves la formación de un ejército moderno, reclutado entre los fellahin, para sustituir a los albaneses que vinieron con él a Egipto, ya los que envió a la conquista del Sudán para evitar sublevaciones en su seno.

Los historiadores Laurens y Gillispie (1989:329) diferencian dos épocas en el gobierno de Mehemet Alí. Durante la primera, que ocuparía sus primeros años en el poder, Mehemet se presenta ante el Imperio Otomano como un reformador al estilo de los fundadores del Imperio, ignorando los tres siglos de evolución política y económica transcurridos desde entonces. Una muestra de este talante es la realización de grandes obras públicas o la creación de monopolios económicos sobre la producción agrícola y artesana. Sin embargo, a partir de 1820, el Virrey comienza a buscar el apoyo de la opinión pública europea —en particular, la francesa - . Resultado inmediato de esta política es la organización de una propaganda sistemática, desde Egipto, que le presenta como «el continuador musulman de la obra de Bonaparte». Citando textualmente a Laurens, «(Mehemet Alí) aime à s' entretenir avec les consuls et les voyageurs européens».

En una hábil política, el Virrey se presenta ante el Imperio Otomano como defensor del Islam, y ante los europeos como fiel a la Revolución Francesa. La obra de Rifa'a al-Tahtawi, un árabe partidario de la Ilustración que escribe las impresiones de su viaje a Francia, es mandada traducir por Mehemet Alí al árabe (1834) y al turco (1839) y distribuida entre sus 
funcionarios. La obra de Tahtawi era una defensa decidida de la civilización de Egipto, idea que se convierte en uno de los componentes esenciales de la dinastía de Mehemet Alí.

Los asesores franceses, griegos, españoles de los que se rodea Mehemet Alí están ahí para ayudarle en esa tarea de modernización de Egipto. En este contexto, adquiere un significado más claro la relación del Virrey con el consulado de España en Alejandría y con Antonio Estéfani, y el regalo del valioso sable a este último.

Antonio Estéfani de Castro, nacido en Madrid en 1.794, fue Cónsul en Alejandría entre el 15 de Enero de 1.832 y el 11 de Diciembre de 1.833, en que es nombrado Cónsul en Trípoli. A comienzos de 1.834 es recibido en audiencia por Mehemet Alí, al que comunica su traslado. En el curso de la entrevista, Estéfani dice haber tenido «(...) la grata satisfacción de recibir de Mehemet Alí los más halagüeños agasajos, distinciones y demostraciones personales mui (sic) particulares, como siempre que le he visitado(...)», según relata en carta dirigida a D. Francisco de Cea Bermúdez y fechada en El Cairo el 14 de enero de 1834.

Hay, además, otro punto de relación entre Estéfani y Mehemet Alí, toda vez que el primero recibió el permiso correspondiente de la reina María Cristina para casarse con $\mathrm{D}^{\mathrm{a}} \mathrm{Ma}$ nuela de Sequera, cuyo padre, Antonio de Sequera y Carvajal, estuvo desde 1830 al servicio del Virrey de Egipto, en calidad de Instructor Jefe de Artillería. Por razones que desconocemos, tal matrimonio no llegó a producirse. El regalo del arma damasquinada por parte de Mehemet Alí sería una muestra clara de las buenas relaciones existentes entre el Virrey y Estéfani, confirmadas en la carta escrita a su superior Cea Bermúdez.

Años después, en 1838, Estéfani solicita y obtiene una nueva Licencia de Matrimonio, en esta ocasión con $\mathrm{D}^{\mathrm{a}}$ Prudencia de Bouligny y Fonseca. Hay entre ambos alguna relación de parentesco, ya que un tal D. Francisco de Bouligny apoya en 1838 una solicitud de licencia «de su sobrino D. Antonio Estéfani» dirigida en España a la Primera Secretaría del Despacho de Estado.

Llegaríamos así al último propietario del sable, el Capitán de Artillería D. Joaquín Bouligny, un familiar a quien Estéfani se lo regala en vida y que finalmente lo cederá al Museo del Ejército en 1848.

\section{CONCLUSIONES}

1. El alfanje de Mehemet Alí, después del estudio científico realizado, ha quedado caracterizado y legitimado como auténtico acero de Damasco, de la mejor calidad, fabricado y forjado según las mejores tradiciones del arte de forja de estos legendarios aceros.

2. La traducción e interpretación de sus leyendas impresas en los damasquinados de oro demuestran que su fabricante fue Assad Allâh Isfahânî en el 870 de la Hégira (1465-1466 d.C.). Concretamente es el segundo más antiguo registrado hasta ahora como perteneciente a este maestro herrero persa.

3. Teniendo en cuenta las analogías que este arma presenta con la espada del Museo de Arte Islámico de El Cairo, con los dibujos de Armas Mamelucas realizados por el equipo de científicos que acompañó a Napoleon Bonaparte en la expedición a Egipto, y el tipo de anillos que presenta su vaina, puede encuadrarse la espada en el estilo del armamento mameluco.

4. El alfanje no fue realizado para un Sultán Mameluco. Por su fecha de fabricación, se trataría del sultán Khushqadam al-Zahir Sayf al-Din, que gobernó en Egipto entre 1461 y 1467 d.C., durante el período Burji (1382-1517 d.C.) Los objetos que se realzaban para la corte Burji llevan como inscripciones, además del nombre y títulos del gobernante al que se destinan, un repertorio de frases honoríficas ( Padre de los pobres», «mantenedor de la justicia entre todos», que Dios haga su victoria gloriosa»). Frases similares aparecen 
en las inscripciones de la Espada del Museo del Cairo ya mencionada y que tantas analogías estilísticas presenta con la de Mehemet Alí, realizada para el sultán Tumambay. En nuestro caso, los textos son alabanzas a Dios y la firma del artesano que la realiza.

5. Por su alto grado de calidad, debió ejecutarse para un personaje importante del estamento militar mameluco y se habría conservado como un objeto valioso hasta llegar a manos del Virrey de Egipto en el siglo XIX. A partir del año 1517, en que cae el gobierno mameluco de Egipto y el control del poder pasa a los turcos otomanos, los mamelucos — haciendo gala de una habilidad notable para mantenerse cerca de los centros de decisión- pasaron a integrar el cuerpo de asesores o beyes del Bajá que nombraba Constantinopla. En este status se mantuvieron hasta que Mehemet Alí, en 1811, les hizo asesinar en masa, acusándoles de mantener actitudes excesivamente independientes respecto de su jefe inmediato.

6. Mehemet Alí regaló la espada al cónsul español en Alejandría, Antonio Estéfani, dentro de su política de buenas relaciones con los cónsules europeos para la modernización de Egipto.

7. La belleza y calidad de su hoja, unidos a su antigüedad, le hacen ser una de las mejores piezas de acero de Damasco conocidas actualmente. Su ajustada composición en carbono del $1,65 \%$ en peso y la ausencia de impurezas, así como la microestructura de temple caracterizada por cementita primaria globulizada y perlita fina parcialmente globulizada, demuestran la maestría del artesano y unos conocimientos profundos de la metalurgia de un acero tan complejo como este.

8. El revenido de la zona de la empuñadura, para aumentar la tenacidad, refleja una sofisticación en los tratamientos térmicos dignos de un gran maestro como Assad Allâh Isfahânî, que conocía bien la concentración de tensiones en esa zona en el momento del impacto de la hoja acerada.

9. La restauración del conjunto y la investigación histórica realzadas han permitido la puesta en valor de un objeto poco resaltado hasta ahora y deseamos que anime a otros estudiosos a profundizar y completar lo aquí presentado.

\author{
A. MOYANO \\ Departamento de Historia Antigua. Facultad de Geografía e Historia. Universidad Complutense de Madrid. \\ F. FERRO \\ Departamento de Historia de América. Facultad de Geografía e Historia. Universidad Complutense de Madrid. \\ G. GONZÁLEZ \\ Departamento de Historia Medieval. Facultad de Geografía e Historia. Universidad Complutense de Madrid. \\ R. Calabrés, D. Arias, J. M. JimÉnez, J. A. Martínez y A. J. CRiado \\ Departamento de Ciencia de los Materiales e Ingeniería Metalúrgica. Facultad de Ciencias Químicas. Uni- \\ versidad Complutense de Madrid.
}

\title{
FUENTES MANUSCRITAS
}

1. Archivo del Ministerio de Asuntos Exteriores: Base de datos «Personal», Registro «P-88», $\mathrm{N}^{\circ}$ de Expediente 04327.

2. Archivo del Ministerio de Asuntos Exteriores: «Guía de Forasteros» anual desde 1805 hasta 1809. 


\section{BIBLIOGRAFÍA}

AI-SAYYID MARSOT, A.L. (1984): Egypt in the reign of Mehemet Alí. Cambridge University Press. ATIL, E. (1981): Renaissance of Islam. Art of the Mamluks, Smithsonian Institution Press, Washington.

AyAlon, D. (1977): Studies on the Mamluks of Egypt (1250-1517). Variorum Reprints. Londres.

BAER, E. (1968): «Fish-pond Ornaments on Persian and Mamluk Metal Vessels», Bulletin of School of Oriental and African Studies, XXXI: 14- 27.

BADíA LeBlich, D. (1996): Viajes de Alí Bey. Madrid.

BARRETT, D. (1947): Islamic Metalwork in the British Museum. London.

BLunT, W. (1966): Isfaham, Pearl of Persia. London.

CRESWELL, K.A.C. (1956): A Bibliography of Arms and Armour in Islam, Londres.

CRiado, A. J., Martínez, J.A., CAlabrés, R. y ARIAS, D. (1997): «El secreto del acero de Damasco». Investigación y Ciencia, 244: 16-25. Barcelona.

Elgood, R. (ed.) (1979): Islamic Arms and Armour, Londres.

Elwell-SutTON, L.D. (1971): «Persian Armorial Inscriptions». Actas del IV Congreso de Estudios Árabes e Islámicos (Lisboa-Coimbra, 1965):573-576. Leiden.

JACKSON, P. (ed.): The Cambridge History of Iran VI: The Timueid and Safavid Periods. Cabridge.

$\mathrm{J}_{\mathrm{ACOB}}$ A. (1985): Les armes blanches du monde islamique. Armes de poing: épées, sabres, poignard, couteaux. París.

KALUS, L. (1980): «Inscriptions arabes et persanes sur les armes musulmanes de la Tour de Londres» Gladius XV: 19-78.

Kassis, H. E. y Kobbervig, K .I. (1987): Las concordancias del Corán, Madrid.

LAMBton, A. K. S. (1954): Islamic Society in Persia. London.

Laurens, H., Gillispie, C. et Alíi (1989): L' Expédition d' Egypte: 1798-1801, Armand Colin editions. Paris.

Mann, J.: A European Sword of the late XIVth Century with an Arabic Inscription, Mayer Memorial Volume. Jerusalén.

Martín, L., Criado, A.J.; Martínez, J.A.; CAlabrés, R. (1995): «Metallographical study of the mechanical properties improvement in a FE-1,3C steel by thermomechanical treatments» Praktische Metallographie 32, 12:625-632.

MAYER, L. A. (1943): «Saracenic Arms and Armour» Ars Islamica: 1- 13.

MAYER, L. A. (1962): Islamic Armourers and Their Works, Ginebra.

MELIKIAN-ChIRVANI, A. S. (1982): Islamic Metalwork from the Iranian World. 8-18th centuries. Victoria and Albert Museum Catalogue. London.

NORTH, A. (1985): An Introduction to Islamic Arms. Londres.

SELIM, A. (1974): Egipto, 5000 años de antigüedad. Madrid.

Smith, C. S. (1960): A History of Metallography. The University of Chicago Press. Chicago.

StOKLEIN, H. (1938): «Arms and Armour», en A Survey of Persian Art, vol. VI: 2555-2585. Pope A. U. (ed.) Oxford.

VV.AA. (1960): Encyclopaedia of Islam (New edition) Tomo I: 685. Vox «Assad Allah Isfahani». Leiden.

VV.AA. (1994): Description de l' Egypte. (Publié par les ordres de Napoleon Bonaparte), Edición íntegra de Benedikt Taschen. Koln.

VerhoeVen, J. D. y Jones, L. L. (1987): «Damascus Steel. Part I-II», Metallography n 20: 145-180.

Verhoeven, J. D. y Jones, L.L. (1990): «Damascus Steel. Part III: The Wadsworth-Sherby Mechanism» Materials Characterization 24: 153- 180.

ZAKI, A. (1966): «Important swords in the Museum of Islamic Art in Cairo» Vaabenhistoriske Aarboger, XIII: 153-157. 